\title{
EXISTENCE RESULTS FOR SOLUTIONS TO DISCONTINUOUS DYNAMIC EQUATIONS ON TIME SCALES
}

\author{
SANKeT TIKARE AND IgUER Luis DOMINI DOS SANTOS
}

Abstract. In this paper, we present three results about the existence of solutions to discontinuous dynamic equations on time scales. The existence of Carathéodory type solution is produced using convergence and Arzela-Ascoli theorem. The Banach's fixed point theorem is used to investigate the existence and uniqueness of solutions and using Schaefer's fixed point theorem we establish the existence of at least one solution. Our results generalizes and extends some existing theorems in this field.

Mathematics subject classification (2010): 26E70, 34A36, 34N05.

Keywords and phrases: Existence of solutions, dynamic equations, time scales, Carathéodory function, fixed point theorem.

\section{REFERENCES}

[1] S. ABвAS, Qualitative analysis of dynamic equations on time scales, Electron. J. Differential Equations, 2018(51), (2018), 1-13.

[2] M. Bohner And A. C. Peterson, Dynamic Equations on Time Scales: An Introduction with Applications, Birkhäuser, Boston, 2001.

[3] M. Bohner And A. C. Peterson, Advances in Dynamic Equations on Time Scales, Birkhäuser, Boston, 2004.

[4] L. Bourlin and E. Trélat, General Cauchy-Lipschitz. Theory for $\Delta$-Cauchy Problems with Carathéodory Dynamics on Time Scales, J. Differ. Equ. Appl. 20, 4 (2014), 526-547.

[5] A. CABADA AND D. R. Vivero, Expression of the Lebesgue $\Delta$-Integral on Time Scales as a usual Lebesgue Integral: Application to the Calculus of $\Delta$ Antiderivatives, Math. Comput. Modelling 43, (2006), 194-207.

[6] M. Cichoń, I. Kubiaczy K, A. SiKorska-NowaK AND A. YAnTiR, Existence of Solutions of the Dynamic Cauchy Problems in Banach Spaces, Demonstratio Math. 45, 3 (2012), 561-573.

[7] Q. Dai And C. C. Tisdell, Existence of Solutions to First Order Dynamic Boundary Value Problems, Int. J. Difference Equ. Vol. 1, 1 (2006), 1-17.

[8] H. Gilbert, Existence Theorems for First-Order equations on Time Scales with $\Delta$-Carathéodory Functions, Adv. Difference Equ., 2010 (2010), Article ID 650827, 20 pages.

[9] A. Granas And J. Dugundu, Fixed Point Theory, Springer-Verlag, New York, 2003.

[10] Z. GRANDE, On an Integral Equation, Math. Pannon. z4, 1 (1993), 95-101.

[11] G. S. Guseinov, Integration on Time Scales, J. Math. Anal. Appl. 285 (2003), 107-127.

[12] S. HiLGER, Ein Maßkettenkalkül mit Anwendung auf Zentrumsmannigfaltigkeiten, Dissertation, Univ. Würzburg, 1988 (in German).

[13] S. HiLger, Special functions, Laplace and Fourier transform on measure chains, Dynam. Systems and Appl, 8, 3-4 (1999), 471-488, Special Issue on "Discrete and Continuous Hamiltonian Systems".

[14] B. KARPUZ, On the existence and uniqueness of solutions to dynamic equations, Turk. J. Math. 42 (2018), 1072-1089.

[15] I. KubiacZy K AND A. Sikorska-Nowak, Existence of Solutions of the Dynamic Cauchy Problem on Infinite Time Scale Intervals, Dis. Math. DICO 29 (2009), 113-126.

[16] A. C. Peters On AND C. C. Tisdell, Boundedness and Uniqueness of Solutions to Dynamic Equations on Time Scales, J. Differ. Equ. appl. 10, 13-15 (2004), 1295-1306. 
[17] I. L. D. Santos And G. N. Silva, Absolute Continuity and Existence of Solutions to Dynamic Inclusions in Time Scales, Math. Ann. 356, 1 (2013), 373-399.

[18] I. L. D. SAntos, Discontinuous Dynamic Equations on Time Scales, Rend. Circ. Mat. Palermo 64, 3 (2015), 383-402.

[19] I. L. D. SAntos, On Qualitative and Quantitative Results for Solutions to First-Order Dynamic Equations on Time Scales, Bol. Soc. Mat. Mex. Vol. 21, (2015), 205-218.

[20] B. SAtco, A Cauchy Problem on Time Scales with Applications, An. Stiint. Univ. Al. I. Cuza Iasi. Mat. (N.S.) Matematica, Tomul LVII, 2011, Supliment, 221-234.

[21] B. Satco, Dynamic Equations on Time Scales seen as Generalized Differential Equations, Bulletin of the Transilvania University of Brasov Series III: 5, 54 (2012), 247-258.

[22] D. Smart, Fixed Point Theorems, Cambridge Tracts in Mathematics, Cambridge University Press, 1974.

[23] A. SLAVík, Dynamic equations on Time Scales and Generalized Ordinary Differential Equations, J. Math. Anal. Appl. 385 (2012), 534-550.

[24] S. TIKARE, Generalized first order dynamic equations on time scales with $\Delta$-Carathéodory functions, Differ. Equ. Appl. 11, 1 (2019), 167-182.

[25] C. C. TISDELL, Existence and uniqueness to nonlinear dynamic boundary value problems, Cubo, 8 , 03 (2006), 11-23.

[26] C. C. TISDEll AND A. ZAIDI, Basic qualitative and quantitative results for solutions to nonlinear, dynamic equations on time scales with an application to economic modelling, Nonlinear Anal., 68 (2008), 3504-3524. 